\title{
Mindfulness meditation in the treatment of
}

\section{substance use disorders and preventing future relapse: neurocognitive mechanisms and clinical implications}

REVIEW

\author{
Sarah E Priddy ${ }^{1,2}$ \\ Matthew O Howard ${ }^{3}$ \\ Adam W Hanley, ${ }^{1,2}$ \\ Michael R Riquino ${ }^{1,2}$ \\ Katarina Friberg-Felsted ${ }^{4}$ \\ Eric L Garland ${ }^{1,2}$ \\ 'College of Social Work, Center on \\ Mindfulness and Integrative Health \\ Intervention Development, University \\ of Utah, Salt Lake City, UT, USA; \\ ${ }^{2}$ College of Social Work, University \\ of Utah, Salt Lake City, UT, USA; \\ ${ }^{3}$ School of Social Work, University of \\ North Carolina, Chapel Hill, NC, USA; \\ ${ }^{4}$ College of Nursing, University of \\ Utah, Salt Lake City, UT, USA
}

This article was published in the following Dove Press journal: Substance Abuse and Rehabilitation

\begin{abstract}
Substance use disorders (SUDs) are a pervasive public health problem with deleterious consequences for individuals, families, and society. Furthermore, SUD intervention is complicated by the continuous possibility of relapse. Despite decades of research, SUD relapse rates remain high, underscoring the need for more effective treatments. Scientific findings indicate that SUDs are driven by dysregulation of neural processes underlying reward learning and executive functioning. Emerging evidence suggests that mindfulness training can target these neurocognitive mechanisms to produce significant therapeutic effects on SUDs and prevent relapse. The purpose of this manuscript is to review the cognitive, affective, and neural mechanisms underlying the effects of mindfulness-based interventions (MBIs) on SUDs. We discuss the etiology of addiction and neurocognitive processes related to the development and maintenance of SUDs. We then explore evidence supporting use of MBIs for intervening in SUDs and preventing relapse. Finally, we provide clinical recommendations about how these therapeutic mechanisms might be applied to intervening in SUDs and preventing relapse.
\end{abstract}

Keywords: addiction, mindfulness, reward, relapse, substance use disorders

\section{Introduction}

Substance use disorders (SUDs) are a pervasive public health problem with deleterious consequences for individuals, families, and society. SUDs are characterized by recurrent drug use that results in functional impairment (ie, continuing to use substances despite health problems, inability to meet obligations at work, school, or home due to substance use). ${ }^{1}$ SUD includes alcohol, tobacco, and other drug use disorders. According to the 2016 National Survey on Drug Use and Health, ${ }^{2} 15.1$ million Americans aged 12 or older met criteria for an alcohol use disorder in the past year, whereas 7.4 million met criteria for an illicit drug use disorder. Specifically, marijuana use disorder was the most prevalent illicit drug use disorder (4.0 million American adults), followed by opioid use disorder (2.1 million). In addition to alcohol and illicit drug use, tobacco use continues to be the largest preventable cause of death in the United States, killing

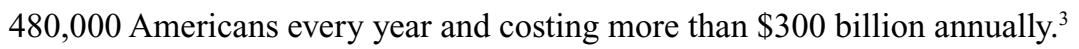

SUDs are associated with medical problems, ${ }^{1}$ mental health disorders, ${ }^{5}$ and higher rates of suicidal ideation and attempts. ${ }^{6}$ In 2016, 64,000 Americans died from overdose. ${ }^{7}$ Additionally, SUDs exact a large economic toll, with crime, loss of productivity,

Correspondence: Eric L Garland College of Social Work, University of Utah, 395 South, 1500 E, Salt Lake City, UT 84112 , USA

Tel + I 80I 58I 3826

Email eric.garland@socwk.utah.edu 
and health care costs due to substance use estimated at more than $\$ 740$ billion annually in the United States. ${ }^{8}$ The high prevalence and devastating impact of SUDs has created an urgent need for access to effective interventions to treat addiction and prevent relapse. However, of the 21 million people needing SUD intervention in 2016, only 3.8 million actually received it, ${ }^{2}$ perhaps as a result of a lack of access to healthcare or motivation. For those who receive intervention, relapse is all too common. Relapse rates for traditional behavioral substance use intervention programs (eg, cognitive-behavioral therapy, motivational interviewing, and 12-step programs), have been estimated to be as high as $60 \%$ in the year following treatment. ${ }^{9,10}$ Thus, new intervention options are sorely needed.

Researchers and clinicians have begun to explore mindfulness-based interventions (MBIs) for intervening in SUDs and relapse prevention. Mounting evidence supports the use of MBIs to address psychiatric disorders. ${ }^{11}$ Building on the first-generation MBIs' (eg, Mindfulness-Based Stress Reduction, MBSR ${ }^{12}$; Mindfulness-Based Cognitive Therapy, $\mathrm{MBCT}^{13}$ success in intervening in stress-related conditions and affective disorders), newer MBIs like Mindfulness-Based Relapse Prevention (MBRP), ${ }^{14}$ and Mindfulness-Oriented Recovery Enhancement (MORE) ${ }^{15}$ use tailored mindfulnessbased intervention strategies to reduce, stop, and prevent substance use. Evidence supporting the efficacy of MBIs as an intervention for SUDs and for relapse prevention is growing. A recent systematic review from Sancho et al ${ }^{16}$ included 54 randomized controlled trials (RCTs) targeting either substance or behavioral addictions. Results revealed MBIs (eg, MBRP; Mindfulness Training for Smokers, MTS; MORE, Acceptance and Commitment Therapy, ACT; Yoga) reduced substance dependence and craving, as well as other addiction-related symptoms (eg, pain, health-related quality of life, depression, and anxiety) through improving mood state and emotion dysregulation. Despite promising preliminary evidence of MBI efficacy, Sancho et al ${ }^{16}$ concluded the most effective intervention approach is likely to involve combining MBIs with treatment-as-usual (TAU) or other active treatments, while also calling for more rigorous research designs with longer follow-up periods.

Similar conclusions were reached in Li et al's ${ }^{17}$ review of 34 MBI RCTs for addiction intervention and relapse prevention. Despite significant differences between studies with regard to sample demographics, mindfulness and control conditions studied, and outcome measures, Li et $\mathrm{al}^{17}$ found MBI involvement (eg, brief, laboratory-based mindfulness inductions, MTS, MORE, Mindfulness Integrative Body-Mind
Treatment) resulted in significantly greater improvement at post-treatment and follow-up assessments than comparator conditions in the majority of trials. Meta-analytic findings revealed effect sizes (ie, Cohen's $d$ and odds ratios [ORs]) ranged from small to large for substance use, stress, and craving outcomes. Of the 34 RCTs in the meta-analysis, 19 included participants who were actively engaged in substance use (eg, tobacco use disorder, alcohol use disorder and at-risk alcohol use behavior, cocaine use disorder, marijuana use disorder, opioid misuse). Of those 19 RCTs, 15 RCTs found mindfulness significantly reduced substance use relative to controls, ${ }^{18-32}$ and five RCTs found mindfulness significantly reduced craving compared to the control condition. ${ }^{19,20,31,33,34}$ In addition, Li et $\mathrm{al}^{17}$ reviewed studies of mindfulness for relapse prevention. Fifteen of the included RCTs studied mindfulness as a relapse prevention strategy, with six RCTS reporting mindfulness (eg, MBRP, MORE, and Mindful Awareness in Body-Oriented Therapy) significantly reduced substance use compared to a control group ${ }^{21,35-39}$; four reported mindfulness reduced craving relative to controls,,$^{21,40-42}$ and two reported reductions in relapse risk. ${ }^{36,43}$

With accumulating evidence supporting the efficacy of MBIs, the purpose of this paper is to review the cognitive, affective, and neural mechanisms underlying the effects of MBIs on SUDs. Here we also provide clinical recommendations about how these therapeutic mechanisms might be applied to intervening in SUDs and preventing relapse. In this review, we first briefly discuss the etiology of addiction and neurocognitive processes related to the development and maintenance of SUDs. We then discuss how mindfulness training intervenes in SUDs and prevents relapse, and review evidence of the mechanisms and efficacy of MBIs for intervening in substance use and preventing relapse.

\section{A neurocognitive perspective on the etiology of SUDs}

Alcohol and drug use disorders may be understood through a 3-stage cycle of addiction: preoccupation/anticipation, binge/intoxication, and withdrawal/negative affect. ${ }^{44}$ This cycle creates allostatic neuroadaptations in the brain's reward and stress systems, which ultimately lead to decreased responsiveness to natural rewards, increased sensitivity to stress, and automatic, conditioned responses to drug cues that drive substance use behavior. Initially, dopamine release in the brain's reward system (ie, ventral striatum and ventral tegmental area $)^{45-48}$ positively reinforces substance use, which facilitates associative learning. ${ }^{48}$ As a result of this Pavlovian conditioning, the rewarding, euphoric experiences occasioned 
by substance use are associated with environmental cues contemporaneous with substance use (eg, specific settings where the substance has been used, people the substance has been used with, or negative emotional states preceding substance use). Over time, greater quantities of dopamine are released in response to these conditioned environmental stimuli (ie, substance cues) than are produced by the pharmacologic properties of the substance; this cue-dependent dopamine release results in craving for the substance, ${ }^{49}$ substance-seeking behavior, and binge substance use. ${ }^{50-52}$ Though dopamine release will decrease in response to satiation of a natural reward (eg, food, sex, or social interaction), drug cue-elicited dopamine levels continue to rise as a result of recurrent substance use, leading to "automaticity" - the habitual use of substances triggered by substance cues. Over time, recurrent substance use results in neuroplastic changes that render natural rewards (eg, food, sex, social interactions) less reinforcing. This desensitization to natural rewards, or "hedonic dysregulation," leads to a reduced capacity to feel pleasure and reduced motivation to pursue healthful and socially affiliative activities as reward and motivation circuits are hijacked by the drive to seek and consume substances.

Exacerbating this process of addictive automaticity and hedonic dysregulation, chronic substance use also dysregulates key nodes in neural circuits underlying executive functioning, such as the anterior cingulate cortex (ACC) and the dorsal and ventrolateral prefrontal cortex (PFC). ${ }^{53}$ Substance misuse weakens functional connectivity between these cognitive control regions and striatal networks implicated in reward processing and motivation, changes that are associated with blunted positive affect, elevated craving, and higher risk of relapse. ${ }^{54,55}$ Such dysconnectivity between cognitive control and reward systems may thereby contribute to compulsive drug seeking and consumption. Further, chronic substance use also produces maladaptive neuroplasticity in brain stress circuitry (eg, the extended amygdala). As a result, individuals with substance use disorder come to experience "increased reactivity to stress and negative emotion." ${ }^{56,57}$ Gradually, a person may become dependent on substances as a means of regulating the dysphoria and anxiety stemming from increased stress reactivity, ensnaring them deeper into the cycle of addiction.

These neurocognitive processes contribute to craving and elicit substance use behavior long after an individual has stopped using substances. Even when total abstinence is achieved, substance-related cues and negative emotional states can continue to trigger relapse. ${ }^{50,58}$ Thus, interventions are needed to target the manifold processes undergirding substance use disorder and relapse. MBIs hold special promise in that regard.

\section{Mindfulness meditation (MM)}

Mindfulness training is a promising intervention option for SUDs and relapse prevention. ${ }^{17,59}$ Mindfulness can be conceptualized as a state, trait, and practice. ${ }^{60}$ The state of mindfulness is cultivated during mindfulness practice and is characterized by a non-judgmental, non-reactive, presentcentered attention and metacognitive awareness of cognition, emotion, sensation, and perception. . $^{61,62}$

Two primary mindfulness practices are focused attention and open monitoring. Focused attention meditation practice involves attending to an object (eg, the sensation of breathing or walking, parts of the body, or visual stimuli) while acknowledging and letting go of distractions. ${ }^{60}$ Open monitoring meditation practice involves maintaining a metacognitive stance in which the practitioner remains cognizant of both the field of awareness and the flux of internal and external stimuli (eg, thoughts, sensations, emotions, perceptions) arising within that field, without fixating on any specific object of attention. ${ }^{60}$ These practices are often combined during a single meditation session.

As repeated mindfulness practice evokes the state of mindfulness, MBI participants exhibit increases in trait mindfulness over time. ${ }^{63,64}$ Trait mindfulness may be defined as the tendency to exhibit mindful qualities in daily life, including nonreactivity to distressing thoughts and emotions, as well as the tendency to observe and accept one's momentary thoughts, feelings, perceptions, and sensations. ${ }^{65,66}$ So, beyond the context of acute mindful states, mindful traits may decrease cognitive, emotional, and behavioral tendencies that help sustain substance misuse. Indeed, trait mindfulness has been found to be positively associated with heightened executive control functioning, ${ }^{67-69}$ and small but statistically significant negative correlations have been found between trait mindfulness and craving, ${ }^{70}$ as well as substance use. ${ }^{71}$ As individuals with SUDs engage in mindfulness practices within MBIs, they learn to cultivate trait mindfulness, providing a bulwark against substance use and relapse.

\section{Methods}

We conducted a literature search in PubMed, PsychInfo, and Web of Science. We then searched reference lists of included studies. We did not search gray literature. We included the following search string: mindfulness OR mindfulness intervention OR mindfulness-based relapse prevention OR 
mindfulness-based stress reduction OR mindfulness-based cognitive therapy AND substance* use OR alcohol use OR drug use OR cocaine use OR opioid use OR tobacco use OR marijuana use AND mechanism OR neurocognitive. From this search we found 31 relevant records in PubMed, 56 in PsychInfo, and 117 in Web of Science. We included studies which were experimental and quasi-experimental in nature (see Figure 1).

\section{Results}

After reviewing the studies, we included 21 studies in the qualitative synthesis. We grouped these studies into three primary domains - promoting cognitive control or executive functioning (see Table 1), restructuring reward (see Table 2), and decreasing stress reactivity (see Table 3 ).

\section{Promoting cognitive control over automaticity}

Therapeutic effects of MBIs on substance use and relapse prevention may be mediated by the effects of mindfulness training on neurocognitive mechanisms implicated in addiction. From a mechanistic perspective, MBIs have been construed as mental training programs designed to exercise neurocognitive capacities that go awry during the process of addiction. ${ }^{72}$
Hence, the focused attention and open monitoring meditations integral to MBIs can been conceptualized as exercises for strengthening prefrontally-mediated brain circuits integral to cognitive control - circuits whose functions are disrupted by chronic drug use and usurped by drug-related cues during the development of addiction. Cultivation of increased cognitive control capacity through mindfulness practices can allow the individual to gain self-control over automatic substance use behavior. This therapeutic process is theorized to involve increasing functional connectivity between prefrontal control regions and striatal brain circuitry involved in reward processing and habit responses. ${ }^{72}$ Improved communication in this frontostriatal circuit may provide the means by which MBIs can restructure reward processes hijacked during the addictive process. ${ }^{73}$ In this way, MBIs may strengthen a domain-general neurocognitive resource that can be used to modulate the automaticity, hedonic dysregulation, and stress reactivity that undergirds SUDs and relapse. Evidence for these mechanisms is reviewed below.

Multiple domains of investigation suggest that meditation practice promotes executive functioning and cognitive control over automatic habits. Behavioral studies have found that meditation decreased automatic responses on a Stroop task ${ }^{74}$ and habitual cognitive scripts. ${ }^{75}$ With respect to addiction, a

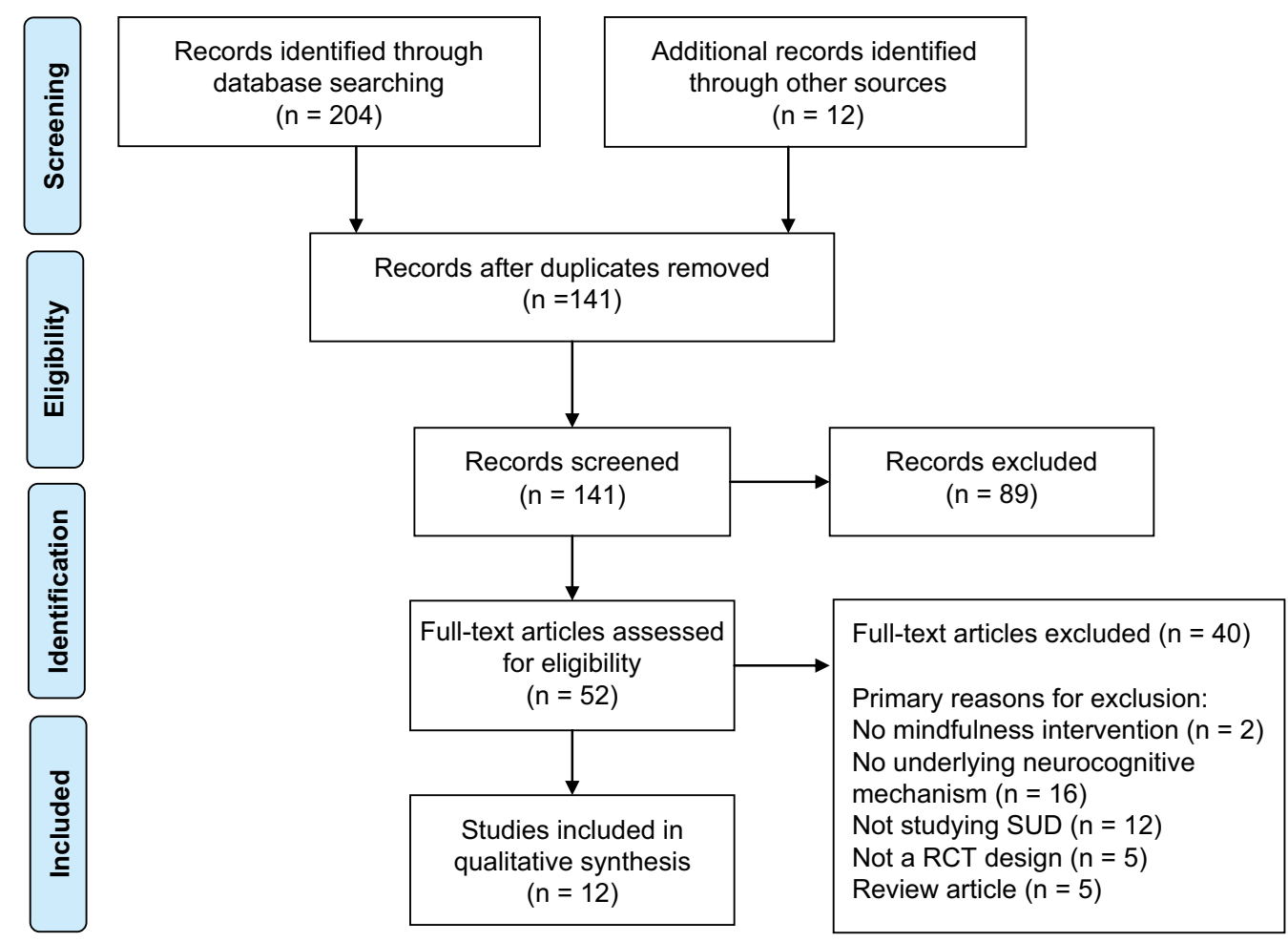

Figure I PRISMA flow diagram.

Note: PLoS Medicine (OPEN ACCESS) Moher D, Liberati A, Tetzlaff J, Altman DG, The PRISMA Group (2009). Preferred Reporting Items for Systematic Reviews and MetaAnalyses: The PRISMA Statement. PLoS Med 6(7): el 000097. doi:10.137I/journal.pmed I000097. ${ }^{109}$

Abbreviations: SUD, substance use disorder; RCT, randomized controlled trials. 
Table I Experimental studies of the impact of mindfulness on executive functioning

\begin{tabular}{|l|l|l|l|l|}
\hline Study & $\begin{array}{l}\text { SUD/addictive } \\
\text { behavior (sample size) }\end{array}$ & MBI & Control condition & Results \\
\hline $\begin{array}{l}\text { Alfonso } \\
\text { et al }\end{array}$ & $\begin{array}{l}\text { Alcohol and polysubstance } \\
\text { use disorder (N=34) }\end{array}$ & $\begin{array}{l}\text { Goal management training + } \\
\text { Mindfulness }\end{array}$ & Standard treatment & $\begin{array}{l}\text { Participants enrolled in GMT + mindfulness } \\
\text { demonstrated significant improvement } \\
\text { in performance on neuropsychological } \\
\text { measures of working memory, response } \\
\text { inhibition, and decision-making when } \\
\text { compared to standard treatment. }\end{array}$ \\
\hline $\begin{array}{l}\text { Garland } \\
\text { et al }{ }^{79}\end{array}$ & $\begin{array}{l}\text { Opioid-misuse among } \\
\text { chronic pain patients } \\
(\mathrm{N}=115)\end{array}$ & $\begin{array}{l}\text { MORE (eight 2-hour group } \\
\text { sessions) }\end{array}$ & $\begin{array}{l}\text { Support group (eight } \\
\text { 2-hour group sessions) }\end{array}$ & $\begin{array}{l}\text { MORE participants demonstrated a } \\
\text { decrease in opioid attentional bias when } \\
\text { compared to support group participants. }\end{array}$ \\
\hline $\begin{array}{l}\text { Tang } \\
\text { et al }\end{array}$ & $\begin{array}{l}\text { Tobacco use disorder } \\
\text { (N=60) }\end{array}$ & $\begin{array}{l}\text { IBMT: 30-minutes practice } \\
\text { training every night for 10 } \\
\text { consecutive nights }\end{array}$ & $\begin{array}{l}\text { Relaxation training: } \\
30 \text {-minutes practice } \\
\text { training every night for } \\
\text { I0 consecutive nights }\end{array}$ & $\begin{array}{l}\text { Participants in the IBMT reported more } \\
\text { efficacy in regulating emotions which were } \\
\text { related to increased ACC/medial prefrontal } \\
\text { cortex (mPFC) activity. }\end{array}$ \\
\hline $\begin{array}{l}\text { Valls- } \\
\text { Serrano } \\
\text { et al }{ }^{77}\end{array}$ & $\begin{array}{l}\text { Polysubstance use } \\
\text { disorder (N=32) }\end{array}$ & GMT + MM + TAU & TAU & $\begin{array}{l}\text { Participants assigned to the GMT + } \\
\text { MM condition demonstrated significant } \\
\text { increases in reflective processes compared } \\
\text { to TAU participants. }\end{array}$ \\
\hline
\end{tabular}

Abbreviations: SUD, substance use disorder; MBI, mindfulness-based interventions; GMT, goal management training; MORE, mindfulness-oriented recovery enhancement; IBMT, integrative body-mind training; ACC, anterior cingulate cortex; MM, mindfulness meditation; TAU, treatment-as-usual; mPFC, medial prefrontal cortex.

Table 2 Experimental studies of the impact of mindfulness on reward

\begin{tabular}{|c|c|c|c|c|}
\hline Study & $\begin{array}{l}\text { SUD/addictive } \\
\text { behavior (sample size) }\end{array}$ & MBI & Control condition & Results \\
\hline Froeliger et $\mathrm{a}^{89}$ & Tobacco use disorder & $\begin{array}{l}\text { MORE (ten } \\
\text { 2-hour } \\
\text { sessions) }\end{array}$ & No treatment & $\begin{array}{l}\text { Compared to the comparison group, MORE } \\
\text { participants demonstrated decreased BOLD } \\
\text { response in ventral striatum (vs) and ventral } \\
\text { prefrontal cortex (vPFC) during a craving } \\
\text { regulation task and increased positive BOLD } \\
\text { signal in vs and vPFC during an emotion regulation } \\
\text { task. }\end{array}$ \\
\hline Garland et $\mathrm{al}^{86}$ & $\begin{array}{l}\text { Opioid misuse among } \\
\text { chronic pain patients } \\
(\mathrm{N}=69)\end{array}$ & $\begin{array}{l}\text { MORE: } 8 \\
\text { weekly, 2-hour } \\
\text { group sessions }\end{array}$ & $\begin{array}{l}\text { Support Group: } 8 \text { weekly, } \\
\text { 2-hour, therapist-led social } \\
\text { support groups based on } \\
\text { the Matrix model IOP } \\
\text { treatment manual }\end{array}$ & $\begin{array}{l}\text { MORE participants demonstrated significantly } \\
\text { greater reductions in opioid cue-reactivity on } \\
\text { the dot probe task, enhancement in heart rate } \\
\text { deceleration during attention to pleasure cues, } \\
\text { and increases in HR variability from rest during } \\
\text { emotional attention to pleasure cues. }\end{array}$ \\
\hline Carroll et al ${ }^{96}$ & $\begin{array}{l}\text { Opioid misuse among } \\
\text { chronic pain patients } \\
(\mathrm{N}=29)\end{array}$ & $\begin{array}{l}\text { MORE: } 8 \\
\text { weekly, } 2 \text {-hour } \\
\text { group sessions }\end{array}$ & $\begin{array}{l}\text { Support Group: } 8 \text { weekly, } \\
\text { 2-hour group sessions }\end{array}$ & $\begin{array}{l}\text { Participation in MORE was associated with } \\
\text { significant increases in LPP response to natural } \\
\text { reward stimuli relative to neutral stimuli. }\end{array}$ \\
\hline Kober et $\mathrm{a}^{98}$ & $\begin{array}{l}\text { Alcohol use disorder } \\
(\mathrm{N}=53)\end{array}$ & $\begin{array}{l}\text { MORE: I0 } \\
\text { weekly, 2-hour } \\
\text { group sessions }\end{array}$ & $\begin{array}{l}\text { Support Group: } 10 \\
\text { weekly, therapist-led } \\
\text { social support groups } \\
\text { based on the Matrix } \\
\text { model IOP tx manual }\end{array}$ & $\begin{array}{l}\text { MORE participants demonstrated a significantly } \\
\text { greater reduction in alcohol attentional bias and } \\
\text { improvement in physiological recovery from } \\
\text { alcohol cues after treatment when compared to } \\
\text { support group participants. }\end{array}$ \\
\hline Paz et $\mathrm{al}^{97}$ & $\begin{array}{l}\text { Opioid misuse among } \\
\text { chronic pain patients } \\
(\mathrm{N}=5 \mathrm{I})\end{array}$ & $\begin{array}{l}\text { MORE: } 8 \\
\text { weekly, } 2 \text {-hour } \\
\text { group sessions }\end{array}$ & $\begin{array}{l}\text { Support Group: } 8 \text { weekly, } \\
\text { 2-hours group sessions }\end{array}$ & $\begin{array}{l}\text { Compared to the support group, MORE } \\
\text { participants demonstrated significantly greater } \\
\text { increases in responsiveness to natural reward } \\
\text { cues relative to drug cues. }\end{array}$ \\
\hline
\end{tabular}

Abbreviations: SUD, substance use disorder; MBI, mindfulness-based interventions; MORE, mindfulness-oriented recovery enhancement; BOLD, blood oxygen level dependent; LPP, late positive potential; IOP, intensive outpatient treatment. 
Table 3 Experimental studies of the impact of mindfulness on stress reactivity

\begin{tabular}{|c|c|c|c|c|}
\hline Study & $\begin{array}{l}\text { SUD/addictive behavior } \\
\text { (sample size) }\end{array}$ & MBI & Control condition & Results \\
\hline $\begin{array}{l}\text { Carroll \& } \\
\text { Lustyk }^{\prime 13}\end{array}$ & Polysubstance use $(\mathrm{N}=34)$ & $\begin{array}{l}\text { MBRP: } 8 \text { weekly, } \\
\text { 2-hour group sessions }\end{array}$ & $\begin{array}{l}\text { Relapse prevention: } 8 \\
\text { weekly, 2-hour group } \\
\text { sessions TAU }\end{array}$ & $\begin{array}{l}\text { Participation in MBRP was associated with } \\
\text { higher cardiac vagal control and lower } \\
\text { stress/anxious reactivity. }\end{array}$ \\
\hline Kober et al ${ }^{114}$ & $\begin{array}{l}\text { Tobacco use disorder } \\
(\mathrm{N}=23)\end{array}$ & Mindfulness training & Freedom from Smoking & $\begin{array}{l}\text { Participants in mindfulness training } \\
\text { demonstrated lower stress-reactivity } \\
\text { compared to the control group. }\end{array}$ \\
\hline Paz et al ${ }^{115}$ & $\begin{array}{l}\text { Tobacco use disorder } \\
(\mathrm{N}=104)\end{array}$ & $\begin{array}{l}\text { Present moment } \\
\text { attention and } \\
\text { awareness training }\end{array}$ & $\begin{array}{l}\text { Cope-as-usual control } \\
\text { condition }\end{array}$ & $\begin{array}{l}\text { Present moment attention and awareness } \\
\text { training was associated with reductions } \\
\text { in psycho-physiological dysregulation in } \\
\text { response to an axiogenic stressor. }\end{array}$ \\
\hline
\end{tabular}

Abbreviations: SUD, substance use disorder; MBI, mindfulness-based interventions; MBRP, mindfulness-based relapse prevention; TAU, treatment-as-usual.

quasi-experimental study found that mindfulness training among polysubstance using individuals led to significant improvements in working memory, selective attention/ response inhibition, and decision-making skills when compared to a TAU control condition. ${ }^{76}$ A pilot RCT replicated these findings,${ }^{77}$ demonstrating that a combination of goal management and mindfulness training improved executive function. A small RCT found that smokers who participated in 2 weeks of mindfulness training demonstrated increased resting state activation in prefrontal and ACC regions involved in cognitive control, neural changes that were correlated with decreases in smoking. ${ }^{18}$ This evidence supports the idea that mindfulness training may decrease substance use behavior by increasing activation in prefrontally-mediated cognitive control networks and thereby facilitate regulation of reactivity to substance cues. In that regard, mechanistic data from a stage $2 \mathrm{RCT}$ for prescription opioid misuse found that MORE significantly decreased subjective and autonomic cuereactivity, ${ }^{78}$ as well as attentional bias, toward opioid cues. ${ }^{79}$

\section{Restructuring reward}

Mindfulness training has also been shown to enhance hedonic experience and positive emotion ${ }^{80-82}$ by cultivating focused attention on natural rewards - a practice called "savoring." 15,83 For example, a brief mindful eating practice increased food liking and enjoyment, while another study found an 8-week mindfulness intervention increased participants' experiences of reward while engaging in pleasant daily life activities. ${ }^{84}$ These studies contribute to the growing body of evidence supporting the "restructuring reward hypothesis," which suggests that mindfulness addresses hedonic dysregulation by increasing natural reward responsiveness, thereby reducing craving and substance use behavior. ${ }^{82}$ In support of this hypothesis, a RCT of opioid-misusing chronic pain patients found eight weeks of MORE increased heart rate variability (HRV) and electrocortical responses to naturally-rewarding images, and these psychophysiological markers were associated with decreased opioid craving. ${ }^{85,86}$ In addition, MORE increased autonomic responses to naturally-rewarding stimuli relative to opioid-related stimuli, and increases in this measure of relative cardiac responsiveness predicted reduced opioid misuse at a 3-month follow-up. ${ }^{87}$ Ecological momentary assessment data collected during this trial supported these psychophysiological findings, indicating MORE increased moment-to-moment positive affect, which predicted decreases in opioid misuse. ${ }^{88}$ Complementary findings have been obtained in a sample of nicotine-dependent smokers participating in a pilot functional magnetic resonance imaging (fMRI) study of MORE. This study found that compared to a time-matched comparison group, participants in MORE demonstrated significant pre- to post-treatment increases in striatal and rostral anterior cingulate ( $\mathrm{rACC}$ ) activation during savoring of natural rewards that significantly predicted reductions in cigarette smoking. ${ }^{89}$ Together, these findings suggest that MBIs may reduce substance use by restructuring reward processes.

\section{Decreasing stress reactivity}

Decades of research demonstrate stress exacerbates substance use. ${ }^{90,91}$ MBIs may ameliorate SUDs and addiction relapse through their stress reductive effects. The effects of MBIs on stress reactivity and recovery have been indexed by HRV, the beat-to-beat variation in heart rate governed by a central-autonomic network implicated in the regulation of attention and emotion ${ }^{92,93}$; HRV is considered to reflect the capacity to self-regulate stress. ${ }^{94,95}$ In a RCT, MBRP increased HRV for individuals diagnosed with SUDs (alcohol, $n=20$; crack cocaine, $n=8$; marijuana, $n=1$; methamphetamine, $n=3$; 
Heroin, $\mathrm{n}=2$ ) compared to TAU and a control condition. ${ }^{96}$ Similarly, brief mindfulness training has been associated with significantly greater HRV increases during exposure to stress in a sample of nicotine-deprived smokers. ${ }^{97}$ In a pilot RCT for alcohol use disorder, participants receiving MORE demonstrated significantly greater HRV recovery from stressprimed alcohol cues. ${ }^{80}$ Extending beyond HRV, a recent RCT examined neural mechanisms of mindfulness-induced stress regulation. Following 8 weeks of mindfulness training, nicotine-dependent smokers demonstrated significantly less amygdala and insula activity during stress exposure than smokers randomized to a control condition, which predicted decreases in smoking 3 months after the intervention. ${ }^{98}$ These studies add to a growing body of evidence that MBIs decrease stress reactivity, further substantiating that mindfulness influences the physiological mechanisms underpinning addiction and relapse.

\section{Clinical application of mindfulness intervention mechanisms for substance use disorder and relapse prevention}

First-generation MBIs (ie, MBSR, MBCT) influenced the development of contemporary MBIs for addiction (ie, MBRP, MORE). Following MBSR, most modern MBIs for addiction are structured as 8-week, group therapy programs, with a format consisting of guided mindfulness practice and debriefing/group process, didactic material, and homework assignments to practice mindfulness skills in the context of everyday life as a means of coping with stress, negative affect, and substance use impulses. Extant MBIs designed specifically to intervene in SUD and relapse prevention differ somewhat from first-generation MBIs in their emphasis, didactic content delivered, duration of home mindfulness practice, and style of debriefing. Modern MBIs for addiction typically provide standard focused attention and open monitoring meditations, as well as mindfulness exercises specifically tailored to address substance craving and substance use habits. Below, we discuss general clinical principles for using MBIs to intervene in SUD and prevent relapse.

\section{Intervening in substance use disorder}

As a result of neurocognitive and interoceptive (ie, awareness of the physiological condition of the body) ${ }^{99}$ deficits, many individuals with SUDs have poor insight into their substance use habits and the negative consequences of their substance use. ${ }^{100}$ As a case in point, the current opioid crisis emerged, in part, from the prescription of opioid analgesics to individuals with chronic pain who were unaware of the addiction liability of these drugs. ${ }^{101}$ Mindfulness practice might help such individuals become aware of automaticity related to their opioid use. For example, by cultivating mindful awareness during the act of taking medication, a patient may begin to notice that she takes higher doses of opioids without intending to when she is lonely or dysphoric. Alternatively, through mindfulness practice, a patient may become aware of escalating use following exposure to opioid-related cues and contexts. Whereas before these patients would associate increased medication use with increases in pain, developing mindfulness through meditation practices may lead to the awareness that their increase in medication use is, in fact, an attempt to self-medicate aversive emotional states or a response triggered by substance-related cues. Similarly, a person who considers himself a social drinker may realize through mindfulness practice that he is drinking more than he intends to, and that his alcohol consumption has serious consequences for his life such as an inability to focus while at work or being disconnected from his family. Thus, in addition to helping individuals with SUDs develop insight into their reasons for substance use, mindfulness can also reveal consequences associated with substance use; for instance, withdrawal symptoms, feelings of shame, relationship problems, and/or deleterious effects on occupational or legal status. Furthermore, mindfulness practice can help individuals gain awareness of how substance cues trigger the experience of craving, resulting in substance use despite adverse consequences and the intent to abstain.

Through gaining awareness of substance use patterns, automaticity of use, and the extent to which they are self-medicating negative affect with substances, individuals can then use mindfulness skills to address their SUD symptoms. They can utilize techniques like mindful breathing, body scan, and mindfulness of everyday life activities to de-automatize substance use habits, strengthen self-regulatory capacity, and thereby exert greater self-control over their behavior. When craving arises, mindfulness practice can deconstruct the experience of craving into its cognitive, affective, and sensorial components. In so doing, the transitory nature of craving is revealed, and one may realize that craving need not inexorably lead to substance use. This technique, also known as "urge surfing" can reduce craving ${ }^{102}$ and decouple craving from subsequent substance use behavior. ${ }^{103}$ This technique can be potentiated by using mindfulness to consciously contemplate positive consequences of abstaining from substance use - a cognitive process that has been shown to downregulate 
craving responses in the striatum by amplifying prefrontal cortical activity. ${ }^{104}$ For example, a woman with polysubstance dependence may be stressed and struggling with whether to accept an invitation to attend a party where she knows the guests will be using alcohol and drugs. Before she decides to attend the party, she could practice mindfulness to decrease stress and become aware of any craving-related thoughts, feelings, and bodily sensations. If she chooses to attend the party, she can use mindfulness to monitor and regulate her experience of craving in response to substance-related cues. However, if she notices she is feeling overwhelmed with craving, she could use mindfulness to disrupt the automatic urge to engage in substance use, and then mindfully respond by taking steps to decrease her risk (eg, leaving the party and calling a supportive friend).

In sum, MM may promote self-awareness and self-regulation of drug-use action schemas, cue-reactivity, substanceseeking behaviors, and substance consumption. By developing trait mindfulness over the course of participating in an MBI, an individual with a SUD may become more aware of how automatic substance use responses operate in daily life. The individual may then evoke the state of mindfulness through focused attention or open monitoring mindfulness practice and choose to respond with a more adaptive coping strategy. Over time, the individual may develop the motivation to reduce substance use or abstain entirely, at which point mindfulness may be useful for preventing relapse.

\section{Preventing relapse}

Given that SUDs are chronically-relapsing conditions, ${ }^{50,58}$ any intervention for substance use should acknowledge the risk of relapse and take steps for prevention. In addition to relapse prevention, individuals with SUDs must also prepare for coping with a relapse. The evidence of mindfulness in the prevention of relapse is limited by high attrition rates in RCTs. For instance, Grant et al's ${ }^{105}$ systematic review and meta-analysis of nine RCTs of mindfulness-based relapse prevention did not detect a statistically significant difference across a range of outcomes (eg, relapse, frequency of use, intervention dropout, depressive symptoms, anxiety symptoms, or mindfulness). However, they did find statistically significant differences in favor of MBRP on withdrawal/ craving symptoms and negative consequences of substance use. The authors call for higher quality RCTs to evaluate the effectiveness of MBIs for relapse prevention.

We argue that mindfulness is particularly suited for relapse prevention. To prevent relapse, individuals may be able to use mindfulness to cultivate an awareness of when substance use habits are triggered by substance cues even after an extended period of abstinence. For instance, monitoring their affective state, and knowing that increased stress, despair, or anger increases relapse risk, the individual may use mindfulness to contemplate the reasons they want to maintain their recovery. A clinical vignette may be illustrative. Consider an opioid-misusing chronic pain patient who used opioids to self-medicate depression and loneliness. After using mindfulness skills to successfully titrate off opioids with the help of her primary care provider, she began exercise therapy which she found helped with her pain and social isolation. One day she has a fall, which landed her in the emergency room with a broken ankle. Without knowing the patient's opioid misuse history, the attending physician unwittingly prescribes an opioid medication and advises the patient to wait several weeks before resuming physical activity. As a result of the self-awareness cultivated through daily mindfulness practice, the patient may recognize the cravings that arise as she holds the prescription slip in her hand. To prevent relapse, she might use mindfulness skills to deconstruct the experience of craving and contemplate the consequences of relapse versus maintaining abstinence. As the craving abates, she may choose to not fill the prescription, use a non-opioid pain reliever, and attend the exercise therapy class for social support even if she cannot participate physically in the exercises.

Mindfulness practice may also ameliorate hedonic dysregulation and thereby reduce risk for relapse. By practicing mindfulness to savor everyday pleasant activities, an individual in recovery from a SUD can self-generate feelings of contentment, relaxation, and joy. Consider an individual with cocaine use disorder in full remission who practices mindful savoring when his grandchildren visit on the weekend. By using mindfulness to focus on the positive emotions and the sense of meaningfulness that emerge from spending time with his grandchildren, this individual may feel more satisfied and contented than he ever did when using substances. Consistent with the reward restructuring hypothesis, by practicing mindful savoring over time, the experience of natural reward may outweigh the drive to use drugs to obtain a sense of wellbeing - fortifying the individual against relapse.

Mindfulness training may also be helpful if a relapse occurs. Consider the case of a man in partial remission from alcohol use disorder who has recently stopped drinking. After successfully abstaining from alcohol for over 2 months after realizing the negative impact his drinking had on his family and work, he attends a party with old friends, where he is overcome by craving and has a drinking lapse. He could 
interpret this lapse as the beginning of a downward spiral into his alcohol use habits, with attendant feelings of shame and hopelessness. Alternatively, he could use mindfulness to disengage from this negative emotional state, arrest the automatic impulse and concomitant experience of craving, and then re-commit himself to recovery by contacting his 12-Step fellowship sponsor. Thus, mindfulness may help to prevent relapse by increasing awareness of high-risk situations, supporting positive hedonic tone, and preventing a singular lapse from becoming a full-blown relapse.

\section{Discussion}

More than a decade of research has demonstrated the promise of MBIs for intervening in SUDs and preventing relapse. Although rigorous trials have been conducted, a number of these studies have methodological limitations that limit the ability to conclusively affirm the effectiveness of mindfulness intervention with SUDs and prevention of relapse. For instance, Sancho et al's ${ }^{16}$ recent systematic review raises the concern that MBI intervention effects do not seem to persist at follow-up assessment. Thus, there remains a need for more large-scale, robust RCTs to reveal the clinical outcomes and therapeutic mechanisms of MBIs for addiction.

Recently, a number of frontiers for research on MBIs have been outlined, including issues pertaining to intervention sequencing, dose-response relationships, and implementation science. ${ }^{103}$ Mindfulness might be integrated into standard cognitive-behavioral interventions for addiction, indeed Bowen et $\mathrm{al}^{43}$ found that MBRP is superior to relapse prevention without mindfulness. Further, Garland et $\mathrm{al}^{40}$ found that MORE is superior to CBT. More studies are needed to determine which of these components are driving intervention effects and perhaps, in what order the components are the most effective. For example, the mindful reappraisal hypothesis states that mindfulness training may prepare people to learn and practice cognitive restructuring. ${ }^{106}$

More studies are needed to determine which of these components are driving intervention effects and perhaps, in what order the components are the most effective. For example, the mindful reappraisal hypothesis states that mindfulness training may prepare people to learn and practice cognitive restructuring. ${ }^{106}$

With regard to implementation science, many studies to date have measured the effectiveness of brief MBIs due to their relative ease of dissemination. Yet, to be optimally efficacious, future intervention development research might consider evolving MBIs beyond a time-limited intervention approach. Despite growing pressure for expediency and increasingly brief intervention, SUDs are chronic conditions that may require prolonged interventions to produce durable change. In that regard, mindfulness might be conceptualized as an integral component of a wellness-oriented lifestyle a catalyst for long-term recovery. Using physical health as an analogy, maintaining a healthy diet and regular exercise across the lifespan is integral to wellbeing. Similarly, mindfulness might need to be practiced on a near daily basis for many years to effectively intervene in addiction and prevent relapse. Research is needed to test the comparative effectiveness of brief versus extended MBIs and the relative costeffectiveness of these models. Given interest in internet- and app-delivered mindfulness interventions, research is needed to determine whether the low dose, brief format of these delivery systems is sufficient to intervene in the chronically relapsing symptoms of SUD. ${ }^{107,108}$ However, if long-term MBIs are shown to produce the greatest clinical benefit, their implementation would require significant change in the current addiction treatment system. Yet, the emerging global emphasis on integrative health supports a holistic approach toward wellness by providing treatment for psychiatric and SUDs in community-based medical settings. MBIs, in brief and extended formats, may be uniquely suited to this therapeutic context, and in time, may become mainstays of addiction treatment.

\section{Acknowledgments}

This work was supported by a grant from the National Institute of Health (NIH) awarded to ELG (R01DA042033). The conclusions in this article are those of the authors and do not necessarily represent the official position of NIH.

\section{Disclosure}

The authors report no conflicts of interest in this work. ELG has conducted MORE training for which he received monetary incentives.

\section{References}

1. American Psychiatric Association. Diagnostic and Statistical Manual of Mental Disorders. 5th ed. Washington, DC: APA; 2013.

2. Hughes A, Williams M, Lipari R, Bose J, Copello E, Kroutil L. NSDUH Data Review 2016; 2016. Available from: https://www.samhsa.gov/ data/sites/default/files/NSDUH-FFR2-2015/NSDUH-FFR2-2015.htm.

3. U.S. Department of Health and Human Services. The Health Consequences of Smoking - 50 Years of Progress: A Report of the Surgeon General. Atlanta: U.S. Department of Health and Human Services, Centers for Disease Control and Prevention National Center for Chronic Disease Prevention and Health Promotion, Office on Smoking and Health; 2014.

4. Bahorik AL, Satre DD, Kline-Simon AH, Weisner CM, Campbell CI. Alcohol, cannabis, and opioid use disorders, and disease burden in an integrated health care system. J Addict Med. 2017;11(1):3-9. 
5. Substance Abuse and Mental Health Services Administration (SAMHSA). Results from the 2013 National Survey on Drug Use and Health: Mental Health Findings. Rockville, MD: SAMHSA; 2014.

6. Wilcox HC, Conner KR, Caine ED. Association of alcohol and drug use disorders and completed suicide: an empirical review of cohort studies. Drug Alcohol Depend. 2004;76(Suppl):S11-19.

7. National Institute on Drug Abuse [NIDA] [webpage on the Internet]. Overdose death rates. National Institute on Drug Abuse; 2017. Available from: https://www.drugabuse.gov/related-topics/trends-statistics/ overdose-death-rates.

8. National Institute on Drug Abuse [NIDA]. Trends \& statistics. Available from: https://www.drugabuse.gov/related-topics/trendsstatistics. Accessed November 15, 2018.

9. Maisto SA, Pollock NK, Cornelius JR, Lynch KG, Martin CS. Alcohol relapse as a function of relapse definition in a clinical sample of adolescents. Addict Behav. 2003;28(3):449-459.

10. Witkiewitz K, Masyn KE. Drinking trajectories following an initial lapse. Psychol Addict Behav. 2008;22(2):157-167.

11. Goldberg SB, Tucker RP, Greene PA, et al. Mindfulness-based interventions for psychiatric disorders: a systematic review and meta-analysis. Clin Psychol Rev. 2018;59:52-60.

12. Kabat-Zinn J. Full Catastrophe Living. NY: Delacorte Press; 1990.

13. Segal Z, Williams JM, Teasdale JD. Mindfulness-Based Cognitive Therapy for Depression. New York: The Guilford Press; 2002.

14. Bowen S, Chawla N, Marlatt GA. Mindfulness-Based Relapse Prevention for Addictive Behaviors. New York: Guilford Press; 2010.

15. Garland EL. Mindfulness-Oriented Recovery Enhancement: Reclaiming a Meaningful Life from Addiction, Stress, and Pain. Washington, DC: NASW Press; 2013.

16. Sancho M, de Gracia M, Rodríguez RC, et al. Mindfulness-based interventions for the treatment of substance and behavioral addictions: a systematic review. Front Psychiatry. 2018;9:95.

17. Li W, Howard MO, Garland EL, McGovern P, Lazar M. Mindfulness treatment for substance misuse: a systematic review and meta-analysis. J Subst Abuse Treat. 2017;75:62-96.

18. Tang YY, Tang R, Posner MI. Brief meditation training induces smoking reduction. Proc Natl Acad Sci U S A. 2013;110(34):13971-13975.

19. Garland EL, Manusov EG, Froeliger B, Kelly A, Williams JM, Howard MO. Mindfulness-oriented recovery enhancement for chronic pain and prescription opioid misuse: results from an early-stage randomized controlled trial. J Consult Clin Psychol. 2014;82(3):448-459.

20. Davis JM, Manley AR, Goldberg SB, Smith SS, Jorenby DE. Randomized trial comparing mindfulness training for smokers to a matched control. J Subst Abuse Treat. 2014;47(3):213-221.

21. Bowen S, Chawla N, Collins SE, et al. Mindfulness-based relapse prevention for substance use disorders: a pilot efficacy trial. Subst Abus. 2009;30(4):295-305.

22. Brewer JA, Mallik S, Babuscio TA, et al. Mindfulness training for smoking cessation: results from a randomized controlled trial. Drug Alcohol Depend. 2011;119(1-2):72-80.

23. Davis JM, Mills DM, Stankevitz KA, Manley AR, Majeskie MR, Smith SS. Pilot randomized trial on mindfulness training for smokers in young adult binge drinkers. BMC Complement Altern Med. 2013;13(1):215.

24. Davis JM, Goldberg SB, Anderson MC, Manley AR, Smith SS, Baker TB. Randomized trial on mindfulness training for smokers targeted to a disadvantaged population. Subst Use Misuse. 2014;49(5):571-585.

25. Goldberg SB, Manley AR, Smith SS, et al. Hair cortisol as a biomarker of stress in mindfulness training for smokers. J Altern Complement Med. 2014;20(8):630-634.

26. Murphy TJ, Pagano RR, Marlatt GA. Lifestyle modification with heavy alcohol drinkers: effects of aerobic exercise and meditation. Addict Behav. 1986;11(2):175-186.

27. Rogojanski J, Vettese LC, Antony MM. Coping with cigarette cravings: comparison of suppression versus mindfulness-based strategies. Mindfulness. 2011;2(1):14-26.
28. de Dios MA, Herman DS, Britton WB, Hagerty CE, Anderson BJ, Stein MD. Motivational and mindfulness intervention for young adult female marijuana users. $J$ Subst Abuse Treat. 2012;42(1):56-64.

29. Mermelstein LC, Garske JP. A brief mindfulness intervention for college student binge drinkers: a pilot study. Psychol Addict Behav. 2015;29(2):259-269.

30. Murphy CM, Mackillop J. Mindfulness as a strategy for coping with cue-elicited cravings for alcohol: an experimental examination. Alcohol Clin Exp Res. 2014;38(4):1134-1142.

31. Ruscio AC, Muench C, Brede E, Waters AJ. Effect of brief mindfulness practice on self-reported affect, craving, and smoking: a pilot randomized controlled trial using ecological momentary assessment. Nicotine Tob Res. 2015;18(1):64-73.

32. Schuman-Olivier Z, Hoeppner BB, Evins AE, Brewer JA. Finding the right match: mindfulness training may potentiate the therapeutic effect of nonjudgment of inner experience on smoking cessation. Subst Use Misuse. 2014;49(5):586-594.

33. Nosen E, Woody SR. Brief psycho-education affects circadian variability in nicotine craving during cessation. Drug Alcohol Depend. 2013;132(1-2):283-289.

34. Ussher M, Cropley M, Playle S, Mohidin R, West R. Effect of isometric exercise and body scanning on cigarette cravings and withdrawal symptoms. Addiction. 2009;104(7):1251-1257.

35. Hsu SH, Collins SE, Marlatt GA. Examining psychometric properties of distress tolerance and its moderation of mindfulness-based relapse prevention effects on alcohol and other drug use outcomes. Addict Behav. 2013;38(3):1852-1858.

36. Price CJ, Wells EA, Donovan DM, Rue T. Mindful awareness in bodyoriented therapy as an adjunct to women's substance use disorder treatment: a pilot feasibility study. J Subst Abuse Treat. 2012;43(1):94-107.

37. Tuab E, Steiner SS, Weingarten E, Walton KG. Effectiveness of broad spectrum approaches to relapse prevention in severe alcoholism: a long-term, randomized, controlled trial of transcendental meditation. Alcohol Treat Q. 1994;11(1-2):187-220.

38. Witkiewitz K, Greenfield BL, Bowen S. Mindfulness-based relapse prevention with racial and ethnic minority women. Addict Behav. 2013;38(12):2821-2824.

39. Witkiewitz K, Warner K, Sully B, et al. Randomized trial comparing mindfulness-based relapse prevention with relapse prevention for women offenders at a residential addiction treatment center. Subst Use Misuse. 2014;49(5):536-546.

40. Garland EL, Roberts-Lewis A, Tronnier CD, Graves R, Kelley K. Mindfulness-oriented recovery enhancement versus CBT for cooccurring substance dependence, traumatic stress, and psychiatric disorders: proximal outcomes from a pragmatic randomized trial. Behav Res Ther. 2016;77:7-16.

41. Nakamura Y, Lipschitz DL, Kanarowski E, McCormick T, Sutherland D, Melow-Murchie M. Investigating impacts of incorporating an adjuvant mind-body intervention method into treatment as usual at a community-based substance abuse treatment facility. Sage Open. 2015;5(1).

42. Witkiewitz K, Bowen S, Douglas H, Hsu SH. Mindfulnessbased relapse prevention for substance craving. Addict Behav. 2013;38(2):1563-1571.

43. Bowen S, Witkiewitz K, Clifasefi SL, et al. Relative efficacy of mindfulness-based relapse prevention, standard relapse prevention, and treatment as usual for substance use disorders. JAMA Psychiatry. 2014;71(5):547-556.

44. Koob GF, Volkow ND. Neurobiology of addiction: a neurocircuitry analysis. Lancet Psychiatry. 2016;3(8):760-773.

45. di Chiara G. Nucleus accumbens shell and core dopamine: differential role in behavior and addiction. Behav Brain Res. 2002;137(1-2):75-114.

46. Koob GF. Neural mechanisms of drug reinforcement. Ann NY Acad Sci. 1992;654:171-191.

47. Wise RA. Dopamine and reward: the anhedonia hypothesis 30 years on. Neurotox Res. 2008;14(2-3):169-183. 
48. Volkow ND, Koob GF, McLellan AT. Neurobiologic advances from the brain disease model of addiction. $N$ Engl J Med Overseas Ed. 2016;374(4):363-371.

49. Volkow ND, Wang G-J, Telang F, et al. Cocaine cues and dopamine in dorsal striatum: mechanism of craving in cocaine addiction. J Neurosci. 2006;26(24):6583-6588.

50. Weiss F. Neurobiology of craving, conditioned reward and relapse. Curr Opin Pharmacol. 2005;5(1):9-19.

51. Volkow ND, Wang G-J, Fowler JS, et al. Decreased striatal dopaminergic responsiveness in detoxified cocaine-dependent subjects. Nature. 1997;386(6627):830-833.

52. Zhang Y, Schlussman SD, Rabkin J, Butelman ER, Ho A, Kreek MJ. Chronic escalating cocaine exposure, abstinence/withdrawal, and chronic re-exposure: Effects on striatal dopamine and opioid systems in C57BL/6J mice. Neuropharmacology. 2013;67:259-266.

53. Goldstein RZ, Volkow ND. Drug addiction and its underlying neurobiological basis: neuroimaging evidence for the involvement of the frontal cortex. Am J Psychiatry. 2002;159(10):1642-1652.

54. Froeliger B, McConnell PA, Stankeviciute N, McClure EA, Kalivas PW, Gray KM. The effects of N-Acetylcysteine on frontostriatal resting-state functional connectivity, withdrawal symptoms and smoking abstinence: a double-blind, placebo-controlled fMRI pilot study. Drug Alcohol Depend. 2015;156:234-242.

55. Goldstein RZ, Volkow ND. Dysfunction of the prefrontal cortex in addiction: neuroimaging findings and clinical implications. Nat Rev Neurosci. 2011;12(11):652-669.

56. Davis M, Walker DL, Miles L, Grillon C. Phasic vs sustained fear in rats and humans: role of the extended amygdala in fear vs anxiety. Neuropsychopharmacology. 2010;35(1):105-135.

57. Jennings JH, Sparta DR, Stamatakis AM, et al. Distinct extended amygdala circuits for divergent motivational states. Nature. 2013;496(7444):224-228.

58. Stewart J. Psychological and neural mechanisms of relapse. Phil Trans Roy Soc B Biolog Sci. 2008;363(1507):3147-3158.

59. Chiesa A, Serretti A. Are mindfulness-based interventions effective for substance use disorders? A systematic review of the evidence. Subst Use Misuse. 2014;49(5):492-512.

60. Vago DR, Silbersweig DA. Self-awareness, self-regulation, and self-transcendence (S-ART): a framework for understanding the neurobiological mechanisms of mindfulness. Front Hum Neurosci. 2012;6(296):1-30.

61. Garland EL. The meaning of mindfulness: a second-order cybernetics of stress, metacognition, and coping. Complement Health Pract Rev. 2007;12(1):15-30.

62. Lutz A, Slagter HA, Dunne JD, Davidson RJ. Attention regulation and monitoring in meditation. Trends Cogn Sci. 2008;12(4):163-169.

63. Garland EL, Fredrickson B, Kring AM, Johnson DP, Meyer PS, Penn DL. Upward spirals of positive emotions counter downward spirals of negativity: insights from the broaden-and-build theory and affective neuroscience on the treatment of emotion dysfunctions and deficits in psychopathology. Clin Psychol Rev. 2010;30(7):849-864.

64. Hölzel BK, Carmody J, Vangel M, et al. Mindfulness practice leads to increases in regional brain gray matter density. Psychiatry Res. 2011;191(1):36-43

65. Baer RA, Smith GT, Hopkins J, Krietemeyer J, Toney L. Using selfreport assessment methods to explore facets of mindfulness. Assessment. 2006;13(1):27-45.

66. Garland EL, Boettiger CA, Howard MO. Targeting cognitive-affective risk mechanisms in stress-precipitated alcohol dependence: an integrated, biopsychosocial model of automaticity, allostasis, and addiction. Med Hypotheses. 2011;76(5):745-754.

67. Anicha CL, Ode S, Moeller SK, Robinson MD. Toward a cognitive view of trait mindfulness: distinct cognitive skills predict its observing and nonreactivity facets. J Pers. 2012;80(2):255-285.

68. Garland EL. Trait mindfulness predicts attentional and autonomic regulation of alcohol cue-reactivity. J Psychophysiol. 2011;25(4):180-189.
69. Garland EL, Boettiger CA, Gaylord S, Chanon VW, Howard MO. Mindfulness is inversely associated with alcohol attentional bias among recovering alcohol-dependent adults. Cognit Ther Res. 2012;36(5):441-450.

70. Garland EL, Roberts-Lewis A, Kelley K, Tronnier C, Hanley A. Cognitive and affective mechanisms linking trait mindfulness to craving among individuals in addiction recovery. Subst Use Misuse. 2014;49(5):525-535.

71. Karyadi KA, Vanderveen JD, Cyders MA. A meta-analysis of the relationship between trait mindfulness and substance use behaviors. Drug Alcohol Depend. 2014;143(Supplement C):1-10.

72. Garland EL, Froeliger B, Howard MO. Mindfulness training targets neurocognitive mechanisms of addiction at the attention-appraisalemotion interface. Front Psychiatry. 2013;4:173.

73. Garland EL. Restructuring reward processing with mindfulnessoriented recovery enhancement: novel therapeutic mechanisms to remediate hedonic dysregulation in addiction, stress, and pain. Ann NY Acad Sci. 2016;1373(1):25-37.

74. Wenk-Sormaz H. Meditation can reduce habitual responding. Altern Ther Health Med. 2005;11:42-58.

75. Greenberg J, Reiner K, Meiran N. "Mind the trap": mindfulness practice reduces cognitive rigidity. PLoS One. 2012;7(5):e36206.

76. Alfonso JP, Caracuel A, Delgado-Pastor LC, Verdejo-García A. Combined goal management training and mindfulness meditation improve executive functions and decision-making performance in abstinent polysubstance abusers. Drug Alcohol Depend. 2011;117(1):78-81.

77. Valls-Serrano C, Caracuel A, Verdejo-Garcia A. Goal management training and mindfulness meditation improve executive functions and transfer to ecological tasks of daily life in polysubstance users enrolled in therapeutic community treatment. Drug Alcohol Depend. 2016;165:9-14.

78. Garland EL, Froeliger B, Howard MO. Effects of mindfulness-oriented recovery enhancement on reward responsiveness and opioid cuereactivity. Psychopharmacology. 2014;231(16):3229-3238.

79. Garland EL, Baker AK, Howard MO. Mindfulness-oriented recovery enhancement reduces opioid attentional bias among prescription opioid-treated chronic pain patients. J Soc Soc Work Res. 2017;8:311-318.

80. Garland EL, Gaylord SA, Boettiger CA, Howard MO. Mindfulness training modifies cognitive, affective, and physiological mechanisms implicated in alcohol dependence: results of a randomized controlled pilot trial. J Psychoactive Drugs. 2010;42(2):177-192.

81. Garland EL, Bryan CJ, Finan PH, et al. Pain, hedonic regulation, and opioid misuse: modulation of momentary experience by mindfulnessoriented recovery enhancement in opioid-treated chronic pain patients. Drug Alcohol Depend. 2017;173(Suppl 1):S65-S72.

82. Garland EL, Howard MO, Zubieta J-K, Froeliger B. Restructuring hedonic dysregulation in chronic pain and prescription opioid misuse: effects of mindfulness-oriented recovery enhancement on responsiveness to drug cues and natural rewards. Psychother Psychosom. 2017;86(2):111-112.

83. Garland EL, Farb NA, R. Goldin P, Fredrickson BL. Mindfulness broadens awareness and builds eudaimonic meaning: a process model of mindful positive emotion regulation. Psychol Inq. 2015;26(4):293-314.

84. Geschwind N, Peeters F, Drukker M, van Os J, Wichers M. Mindfulness training increases momentary positive emotions and reward experience in adults vulnerable to depression: a randomized controlled trial. $J$ Consult Clin Psychol. 2011;79(5):618-628.

85. Garland EL, Froeliger B, Howard MO. Effects of mindfulness-oriented recovery enhancement on reward responsiveness and opioid cuereactivity. Psychopharmacology. 2014;231(16):3229-3238.

86. Garland EL, Froeliger B, Howard MO. Neurophysiological evidence for remediation of reward processing deficits in chronic pain and opioid misuse following treatment with mindfulness-oriented recovery enhancement: exploratory ERP findings from a pilot RCT. J Behav Med. 2015;38(2):327-336. 
87. Garland EL. Mindfulness-Oriented Recovery Enhancement Modulates Neurocognitive Mechanisms and Reward System Function in Addiction, Stress, and Pain. New York, NY: Sloan Kettering Memorial Hospital; 2015.

88. Garland EL, Bryan CJ, Finan PH, et al. Pain, hedonic regulation, and opioid misuse: modulation of momentary experience by mindfulnessoriented recovery enhancement in opioid-treated chronic pain patients. Drug Alcohol Depend. 2017;173:S65-S72.

89. Froeliger B, Mathew AR, McConnell PA, et al. Restructuring reward mechanisms in nicotine addiction: a pilot fMRI study of mindfulnessoriented recovery enhancement for cigarette smokers. Evid Based Complement Alternat Med. 2017;2017:e7018014.

90. Sinha R Chronic stress, drug use, and vulnerability to addiction. Ann NY Acad Sci. 2008;1141(1):105-130.

91. Koob GF. A role for brain stress systems in addiction. Neuron. 2008;59(1):11-34.

92. Thayer JF, Lane RD. A model of neurovisceral integration in emotion regulation and dysregulation. J Affect Disord. 2000;61(3):201-216.

93. Thayer JF, Lane RD. Claude Bernard and the heart-brain connection: further elaboration of a model of neurovisceral integration. Neurosci Biobehav Rev. 2009;33(2):81-88.

94. Thayer JF, Åhs F, Fredrikson M, Sollers JJ, Wager TD. A meta-analysis of heart rate variability and neuroimaging studies: implications for heart rate variability as a marker of stress and health. Neurosci Biobehav Rev. 2012;36(2):747-756.

95. Holzman JB, Bridgett DJ. Heart rate variability indices as bio-markers of top-down self-regulatory mechanisms: a meta-analytic review. Neurosci Biobehav Rev. 2017;74(Pt A):233-255.

96. Carroll H, Lustyk MKB. Mindfulness-based relapse prevention for substance use disorders: effects on cardiac vagal control and craving under stress. Mindfulness. 2018;9(2):488-499.

97. Paz R, Zvielli A, Goldstein P, Bernstein A. Brief mindfulness training de-couples the anxiogenic effects of distress intolerance on reactivity to and recovery from stress among deprived smokers. Behav Res Ther. 2017;95(Suppl C):117-127.

98. Kober H, Brewer JA, Height KL, Sinha R. Neural stress reactivity relates to smoking outcomes and differentiates between mindfulness and cognitive-behavioral treatments. Neuroimage. 2017;151(Suppl C):4-13.
99. Craig AD. How do you feel? Interoception: the sense of the physiological condition of the body. Nat Rev Neurosci. 2002;3(8): 655-666.

100. Goldstein RZ, Craig AD, Bechara A, et al. The neurocircuitry of impaired insight in drug addiction. Trends Cogn Sci. 2009;13(9):372-380.

101. Chou R, Deyo R, Devine B, Hansen R, Sullivan S, Jarvik J. The Effectiveness and Risks of Long-Term Opioid Treatment of Chronic Pain: Evidence Report/Technology Assessment. Vol. 218. Rockville, MD: Agency for Healthcare Research and Quality; 2014.

102. Bowen S, Marlatt A. Surfing the urge: brief mindfulness-based intervention for college student smokers. Psychol Addict Behav. 2009;23(4): 666-671.

103. Garland EL, Howard MO. Mindfulness-based treatment of addiction: current state of the field and envisioning the next wave of research. Addict Sci Clin Pract. 2018;13(1):14.

104. Kober H, Mende-Siedlecki P, Kross EF, et al. Prefrontal-striatal pathway underlies cognitive regulation of craving. Proc Nat Acad Sci US A. 2010;107(33):14811-14816.

105. Grant S, Colaiaco B, Motala A, et al. Mindfulness-based relapse prevention for substance use disorders: a systematic review and metaanalysis. J Addict Med. 2017;11(5):386-396.

106. Garland EL, Farb NA, Goldin PR, Fredrickson BL. The mindfulnessto-meaning theory: extensions, applications, and challenges at the attention-appraisal-emotion interface. Psychol Inq. 2015;26(4): 377-387.

107. Cavanagh K, Strauss C, Cicconi F, Griffiths N, Wyper A, Jones F. A randomised controlled trial of a brief online mindfulness-based intervention. Behav Res Ther. 2013;51(9):573-578.

108. Garrison KA, Pal P, O'Malley SS, et al. Craving to quit: a randomized controlled trial of smartphone all-based mindfulness training for smoking cessation. Nicotine Tob Res. Epub 2018 Jun 18.

109. Moher D, Liberati A, Tetzlaff J, Altman DG, The PRISMA Group (2009). Preferred Reporting Items for Systematic Reviews and Meta-Analyses: The PRISMA Statement. PLoS Med. 6(7): e1000097.

110. Tang YY, Tang R, Posner MI. Mindfulness meditation improves emotion regulation and reduces drug abuse. Drug and Alcohol Dependence. 2016;163:S13-8.
Substance Abuse and Rehabilitation

\section{Publish your work in this journal}

Substance Abuse and Rehabilitation is an international, peer-reviewed, open access journal publishing original research, case reports, editorials, reviews and commentaries on all areas of addiction and substance abuse and options for treatment and rehabilitation. The manuscript management system is completely online and includes a very quick and fair

\section{Dovepress}

peer-review system. Visit http://www.dovepress.com/testimonials.php to read real quotes from published authors. 